\title{
Treatment of Liver Cancer: Role of the Traditional Mongolian Medicine
}

\author{
Xiaomei Bao, ${ }^{1,2}$ Lu Chen, ${ }^{1}$ Yiman Liu, ${ }^{1}$ Hua Sheng, ${ }^{2}$ Kailong Wang, ${ }^{1}$ Yanming Luo, \\ Tongling Qin, ${ }^{3}$ Ying Liu, ${ }^{3}$ and Yuling Qiu $\mathbb{D}^{3}$ \\ ${ }^{1}$ State Key Laboratory of Component-based Chinese Medicine, Tianjin University of Traditional Chinese Medicine, Tianjin, \\ China \\ ${ }^{2}$ School of Pharmacy, Inner Mongolia Medical University, Hohhot, China \\ ${ }^{3}$ School of Pharmacy, Tianjin Medical University, Tianjin, China
}

Correspondence should be addressed to Yuling Qiu; qiuyuling@tmu.edu.cn

Received 19 November 2021; Accepted 19 January 2022; Published 14 February 2022

Academic Editor: Li-Ping Kang

Copyright (C) 2022 Xiaomei Bao et al. This is an open access article distributed under the Creative Commons Attribution License, which permits unrestricted use, distribution, and reproduction in any medium, provided the original work is properly cited.

Liver cancer is an extraordinarily heterogeneous malignancy with relatively high mortality and increasing incidence rate among the so far identified cancers. Improvements in liver cancer therapy have been made in the past decades, but therapeutics against liver cancer are still limited. Traditional Mongolian Medicine, formed and developed by the Mongolian people to maintain health in the medical practice of fighting against diseases, has been recognized as one of the key components of the world healthcare system. Traditional Mongolian Medicine has been used to treat various malignancies, including liver cancer, for a long time in Asia and its advantages have become more and more apparent. Herein, this review made a comprehensive summary of Traditional Mongolian Medicine, including the ideas in the liver cancer treatment, sources of medicines or prescriptions, traditional applications, modern pharmacological research, chemical structure and mechanisms of several monomer compounds isolated from Traditional Mongolian Medicine, with a view to finding promising drugs against liver cancer and expanding the clinical application of Traditional Mongolian Medicine in liver cancer therapy.

\section{Introduction}

Liver cancer has an insidious onset. Even though many patients have been effectively diagnosed and treated in the early stage of the disease, the recurrence rate is still high $[1,2]$. Especially for patients with advanced disease, the prognosis is not optimistic. If cancer spreads to the peripheral lymph nodes, the patient's 5-year survival rate is only $11 \%$. The current treatment methods for liver cancer include surgery, radiotherapy, minimally invasive treatment (radiofrequency ablation, argon helium knife, microwave ablation, interventional therapy), biological immunotherapy, traditional Chinese medicine, and diet therapy. Surgery is the preferred treatment for liver cancer. However, only $20 \%-30 \%$ of patients can get surgical resection because most patients have basic liver disease, or most of them have reached the advanced stage at the time of diagnosis $[3,4]$.
Although the clinical treatment of liver cancer has been improved in the past years, the overall survival remains unsatisfactory. Especially, patients in the advanced stage still have limited treatment options. Therefore, it is of great significance to further explore the occurrence and development mechanism of liver cancer and find new therapeutics.

Traditional Chinese ethnic medicine is the creation and accumulation of every ethnic minority through their long histories [5]. As an indispensable part of traditional Chinese medicine, Mongolian medicine is an important traditional medicine formed and developed by the Mongolian people in the medical practice of fighting against diseases for a long time and has its own unique diagnostic methods [6]. Mongolian medicine absorbs and digests the theory of Tibetan medicine and other ethnic medicine. It combines its own theories and experience to create the Mongolian 
medicine system with characteristics of Mongolian culture and history. Its development has received the attention of the Chinese government and the support of relevant policies [7].

As the only remaining historical documents, Mongolian medical literature has a complete medical theory system and is still used in clinical practice. The classic books of Mongolian medicine include Ren yao bai jing jian, the Four Medical Tantras, and Classic Canon of Mongolian Materia Medica. Ren yao bai jing jian is the foundation of Mongolian medicine, containing 390 kinds of Mongolian medicines [8]. The Four Medical Tantras is a comprehensive work on Tibetan medicine integrating natural sciences, social sciences, and humanities $[9,10]$. It summarized the theories, diagnosis, and treatment experience of traditional Tibetan medicine [11-13]. Classic Canon of Mongolian Materia Medica makes a comprehensive summary and some revisions of Mongolian medicine herbal books of the past dynasties [14]. This book records 879 kinds of Mongolian medicinal materials, with 570 medicine illustrations [15]. With the development of Mongolian medicine, the experts of Mongolian medicine actively absorbed the knowledge of plant taxonomy, pharmacognosy, natural pharmaceutical chemistry, pharmacology, and other aspects and compiled a series of teaching materials and authoritative books with the support and organization of the government, such as "Mongolian Pharmacy," "Encyclopedia of Mongolian Medicine," "Prescription of Mongolian Medicine," "Drug standard of the Ministry of health of the people's Republic of China (Mongolian medicine volume)," and "Chinese Materia Medica Mongolian Medicine Volume." These modern Mongolian medicine books and standards have made important contributions to the modernization of Mongolian medicine and will benefit mankind.

Although both Mongolian medicine and traditional Chinese medicine are traditional medicine, there are many differences in their sources and clinical uses $[16,17]$. Mongolian medicine covers a wide range of sources, including plants, animals, minerals, and chemicals [7]. There are 511 kinds of medicinal plants in Mongolian medicine, and 23 species-specific for Mongolian medicine are basal plants, such as Flos Scabiosae, Lomatogonium rotatum, Dracocephalum moldevica, etc. [18]. Some medicinal plants are unique to Mongolian medicine and are not available in traditional Chinese medicine [16], such as Punica granatum L., Har Gabur, Gardenia jasminoides, Syringa pinnatifolia, Scabiosa comosa Fisch, wannianhui (made from calcareous lumps of ancient buildings), Flos of Aconitum kusnezoffi, rhaponticum uniflorum, Pearl bar, Oxytropis Myriophylla, etc. Modern pharmacological studies show that Mongolian medicine has good antitumor effects. In the process of chemotherapy, Mongolian medicine can protect normal cells from chemotherapeutic/radiotherapeutic injuries, consolidate or enhance the effect of chemotherapy/radiotherapy, and prevent cancer metastasis and recurrence. This review introduces the ideas of Mongolian medicine in the treatment of liver cancer and the research progress of common clinical drugs (Tables 1 and 2.) and their possible mechanisms.

\section{Treatment Concept}

Every Chinese Minority established their medical system with their own national characteristics based on the living environment, natural resources, national culture, religious beliefs, and so on, which played key roles in preventing disease and maintaining health [28]. Tibetan medicine, Mongolian medicine, Uygur medicine, Zhuang medicine, Hui medicine, Dai medicine, and Miao medicine are important components of traditional Chinese medicine [29]. The holistic view of the basic theory in Mongolian medicine includes two aspects: the unity of man and nature and the unity of the human body itself. The unity of human beings is the most critical factor in maintaining healthy activities in life [30, 31]. Traditional Mongolian medicine not only accepts Chinese ancient native materialism and dialectics thoughts, $\mathrm{Wu}$ yuan, Yin and Yang theory, and absorbs the basic theory of traditional Chinese medicine, but also blends the theory of Tibetan medicine and Indian medicine [32]. In the process of development, it has gradually formed a unique Mongolian medicine theory system, based on the philosophy of Yin and Yang, Wu yuan, Han-re theory; meanwhile, Sangen, Qi-su, San-hui, Zang-fu theory, and Liu-yin theory are considered as the main contents. In the theory of Mongolian medicine, the human body can maintain normal physiological activities mainly because the body has three kinds of energy resources and basic substances, namely, $\mathrm{He}$ (equivalent to air), Badakan (equivalent to soil and water), and Xiri (equivalent to fire), which are thought to be the origin and foundation of human life and are also called Sangen. The San-gen theory holds that the life phenomenon of the human body is a comprehensive and complex activity process, in which the organic coordination of San-gen makes the whole life in an orderly metabolic state. The organic connection between the internal organs and body surface tissues is the result of the effects of the San-gen. Therefore, San-gen is the material basis on which life depends (Figure 1).

The concept of Mongolian medicine has gained international attention and has been gradually accepted by people in other parts of the world [33]. The Four Medical Tantras [34] details the etiology, symptoms, diagnosis, treatment, and prevention of the tumor. It regards the human body as an organic whole and considers the tumor as a systemic disease whose occurrence, development, recurrence, and metastasis are the local reflection of systemic diseases. According to different patients, different etiology, different time, the syndrome differentiation for treatment has been done [8].

Mongolian physicians think that the incidence of liver cancer is due to long-term emotional depression, mental traumas, improper diet, long-term addiction to tobacco and alcohol, and traumatic injury. The essence of the human body cannot be normally operated and then accumulates in the liver. As a result, "San-gen" is disordered in vivo and the transportation of blood in the liver is abnormal and deposits [35]. Body fluid, blood stasis, and hot evil then coagulate, throw the organism out of balance, and generate heat which can consistently fumigate the condensation. Ultimately, "Pi 
TABle 1: Prescriptions for the treatment of liver cancer in Mongolian medicine.

\begin{tabular}{|c|c|c|c|c|c|c|c|}
\hline Prescription & Components & $\begin{array}{c}\text { Treatment } \\
\text { concept }\end{array}$ & $\begin{array}{c}\text { Cell } \\
\text { model }\end{array}$ & $\begin{array}{c}\text { Animal } \\
\text { model }\end{array}$ & $\begin{array}{c}\text { Pharmacologic } \\
\text { action }\end{array}$ & Clinical application & Reference \\
\hline $\begin{array}{l}\text { Qinggan jiuwei } \\
\text { powder }\end{array}$ & $\begin{array}{c}\text { Calculus bovis, } \\
\text { Dianthus superbus, } \\
\text { Trogopterus dung, } \\
\text { Scabiosa comosa, Costus } \\
\text { root, Herpetospermum } \\
\text { seed, Angelica sinensis, } \\
\text { Aristolochia } \\
\text { manshuriensis, Crocus } \\
\text { sativus }\end{array}$ & $\begin{array}{l}\text { Removing heat } \\
\text { from the liver; } \\
\text { cooling blood }\end{array}$ & - & $\begin{array}{l}\mathrm{CCl}_{4^{-}} \\
\text {induced } \\
\text { liver } \\
\text { fibrosis in } \\
\text { rats }\end{array}$ & $\begin{array}{l}\text { Suppress or } \\
\text { alleviate liver } \\
\text { fibrosis }\end{array}$ & $\begin{array}{l}\text { Viral hepatitis, } \\
\text { cirrhosis, fatty liver, } \\
\text { chronic } \\
\text { cholecystitis, } \\
\text { gastroduodenal } \\
\text { ulcer, etc. }\end{array}$ & [19-21] \\
\hline $\begin{array}{l}\text { Honghua qinggan } \\
13 \text { flavors }\end{array}$ & $\begin{array}{l}\text { Saffron, clove, lotus } \\
\text { seeds, radix } \\
\text { ophiopogonis, radix } \\
\text { aucklandiae, Melia } \\
\text { toosendan, Gardenia, } \\
\text { Lignum pterocarri, } \\
\text { musk, pulvis cornus } \\
\text { bubali concentratus, } \\
\text { calculus bovis, and } \\
\text { vermilion }\end{array}$ & $\begin{array}{l}\text { Clearing heat; } \\
\text { detoxifying; } \\
\text { cooling blood }\end{array}$ & - & $\begin{array}{l}\text { CCl4- } \\
\text { induced } \\
\text { liver } \\
\text { fibrosis in } \\
\text { rats }\end{array}$ & $\begin{array}{l}\text { Liver injury and } \\
\text { fibrosis }\end{array}$ & $\begin{array}{l}\text { Liver failure, drug- } \\
\text { induced hepatitis, } \\
\text { alcoholic liver, fatty } \\
\text { liver, etc. }\end{array}$ & {$[22-24]$} \\
\hline Changpu siwei & $\begin{array}{l}\text { Galanga rhizome, } \\
\text { Halitum purpureum, } \\
\text { vladimiriae radix, and } \\
\text { Acorus gramineus }\end{array}$ & $\begin{array}{l}\text { Suppressing } \\
\text { "ba dagan and } \\
\text { he"; relieving } \\
\text { asthma and } \\
\text { pain } \\
\text { Activating }\end{array}$ & $\begin{array}{l}\text { SMMC- } \\
7721 \text { cell }\end{array}$ & - & $\begin{array}{l}\text { Inhibition the } \\
\text { proliferation of } \\
\text { liver cancer cells }\end{array}$ & $\begin{array}{l}\text { Oppression in chest } \\
\text { and dyspnea, } \\
\text { indigestion, } \\
\text { relieving asthma } \\
\text { and pain }\end{array}$ & [25] \\
\hline $\begin{array}{l}\text { Hepatoprotective } \\
\text { Mongolian I }\end{array}$ & $\begin{array}{l}\text { Terminalia chebula is } \\
\text { the main component }\end{array}$ & $\begin{array}{l}\text { blood } \\
\text { circulation, } \\
\text { removing } \\
\text { blood stasis, } \\
\text { and relieving } \\
\text { pain }\end{array}$ & $\begin{array}{l}\text { Huh- } \\
7 \text { cell }\end{array}$ & - & $\begin{array}{l}\text { Inhibition the } \\
\text { proliferation of } \\
\text { liver cancer cells, } \\
\text { inducing } \\
\text { apoptosis }\end{array}$ & $\begin{array}{l}\text { Prevention and } \\
\text { treatment of } \\
\text { tumors }\end{array}$ & {$[26]$} \\
\hline $\begin{array}{l}\text { Hepatoprotective } \\
\text { Mongolian II }\end{array}$ & $\begin{array}{l}\text { Terminalia chebula is } \\
\text { the main component }\end{array}$ & $\begin{array}{l}\text { Activating } \\
\text { blood } \\
\text { circulation, } \\
\text { removing } \\
\text { blood stasis, } \\
\text { and relieving } \\
\text { pain }\end{array}$ & $\begin{array}{l}\text { Huh-7, } \\
\text { HepG2 } \\
\text { cell }\end{array}$ & - & $\begin{array}{l}\text { Inducing } \\
\text { apoptosis and cell } \\
\text { cycle arrest }\end{array}$ & $\begin{array}{l}\text { Prevention and } \\
\text { treatment of } \\
\text { tumors }\end{array}$ & [27] \\
\hline
\end{tabular}

kuai" is gradually formed in the liver and the greater the hot evil, the bigger and harder the block. "Pi kuai" is what we call tumors [36].

\section{Prescription}

3.1. Qinggan Jiuwei Powder. Qinggan Jiuwei Powder (also named Geiwang-9) is a traditional Mongolian medicine prescription for liver diseases. This prescription was first published in the Four Medical Tantras and then spread to Mongolia and has been used till now. It is recorded in "Encyclopedia of Mongolian Medicine," "Prescription of Mongolian Medicine." "Drug Standards of the Ministry of Health of the People's Republic of China (Mongolian Medicines Volume)" [37] and other classic works. This prescription is composed of Calculus bovis, Dianthus superbus, trogopterus dung, Scabiosa comosa, costus root, herpetospermum seed, Angelica sinensis, Aristolochia manshuriensis, and Crocus sativus [38]. It has the efficacy of cooling blood and removing heat from the liver. Currently, it has been widely used in the treatment of viral hepatitis, cirrhosis, fatty liver, chronic cholecystitis, gastroduodenal ulcer, and other diseases. The experimental research mainly focuses on quality control, technological research, and pharmacological effect. Early diagnosis and treatment of liver fibrosis can effectively improve the life quality of patients and prevent them from developing cirrhosis and even liver cancer [39]. Hepatic fibrosis is caused by excessive deposition of extracellular matrix (ECM) in the liver, which eventually leads to hepatic fibrosis. In normal liver, ECM synthesis and degradation remain dynamically balanced as a result of precise regulation of matrix metalloproteinases (MMPs) and their specific inhibitor, TIMPs [40]. Previous studies [19] have found that Qinggan Jiuwei powder has a certain effect on serum TIMP-1 level and can effectively reduce the imaging index LSM and values measured by abdominal color Doppler ultrasound in patients with alcoholic liver fibrosis [20]. Meanwhile, Qinggan Jiuwei 


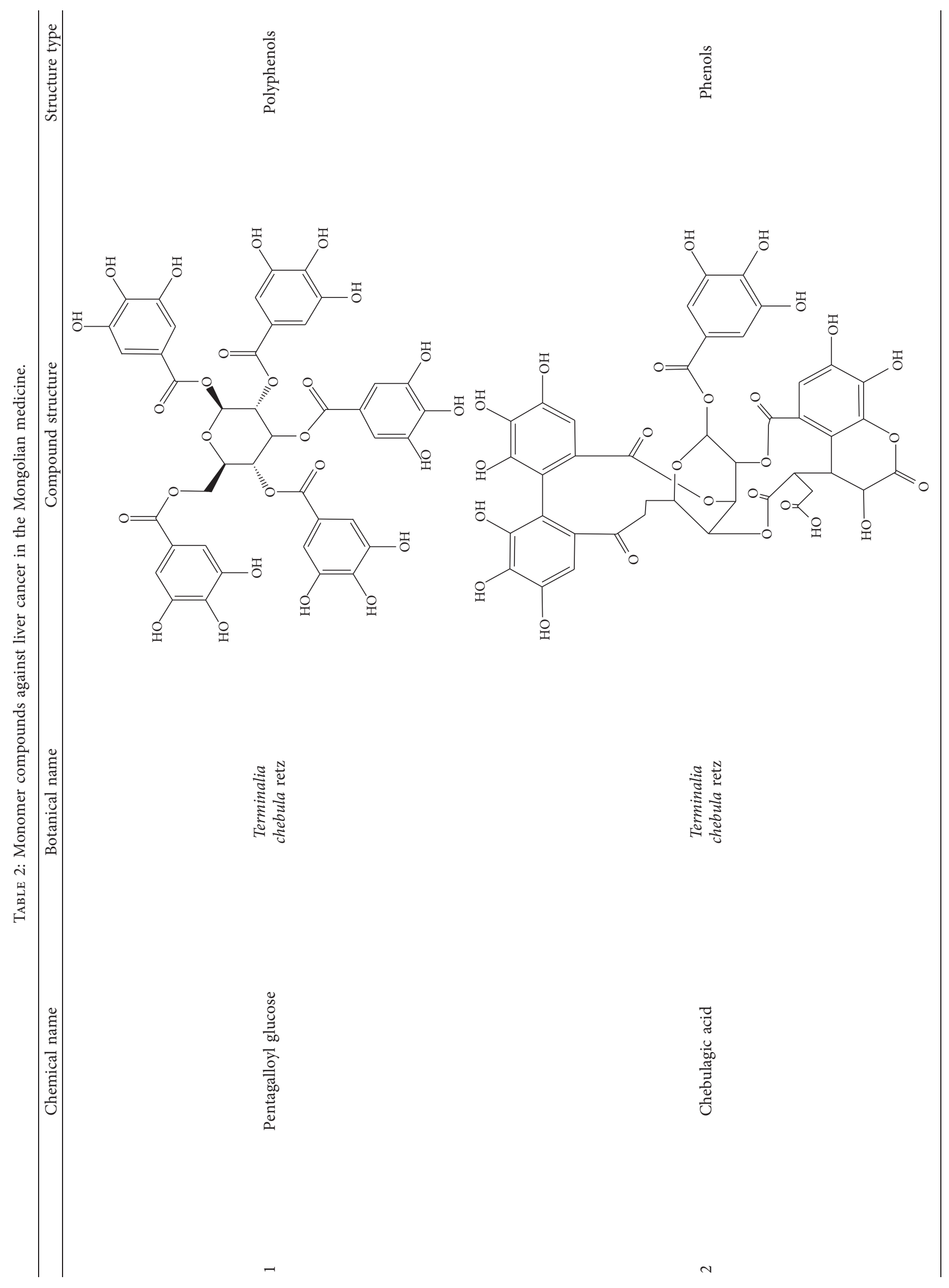




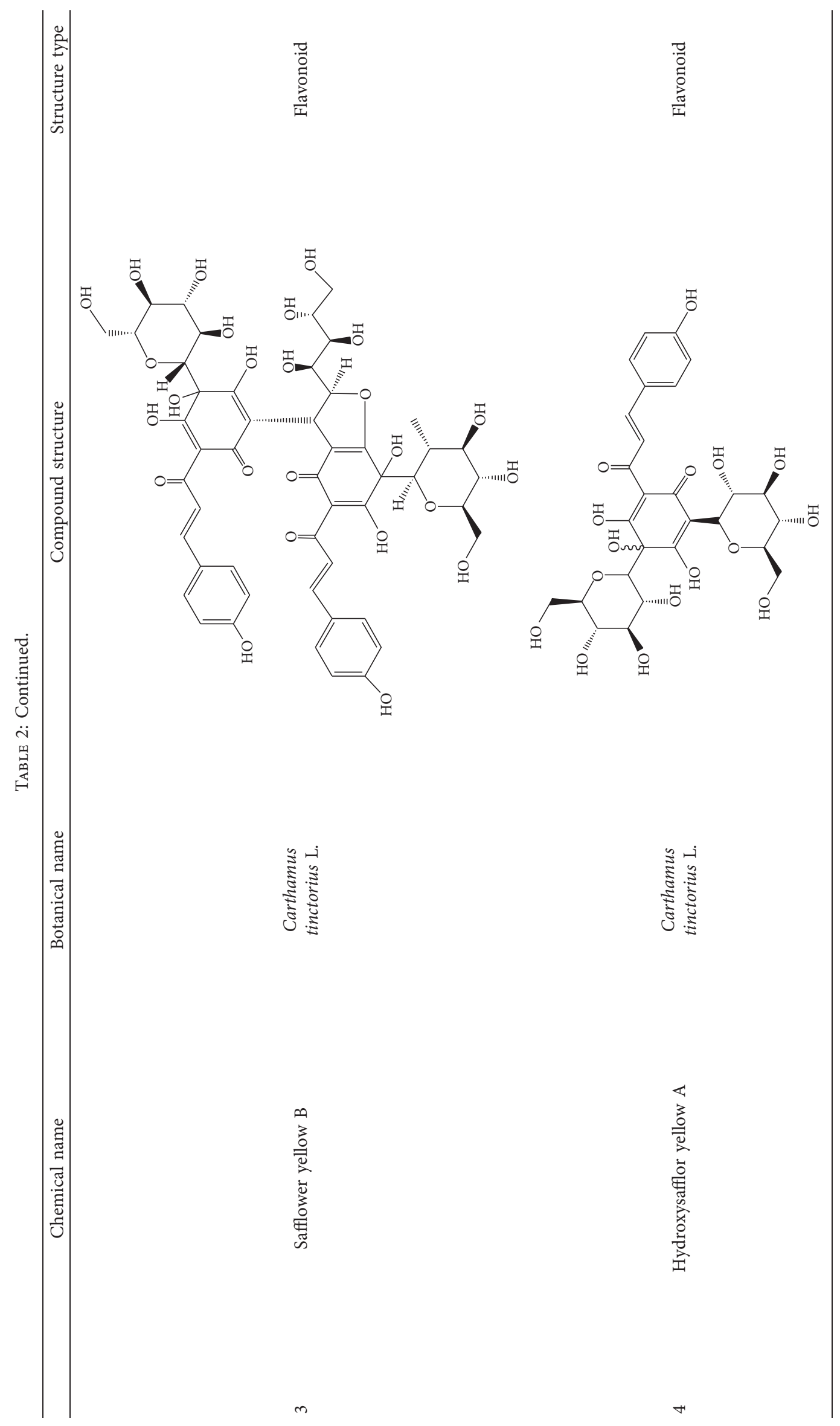




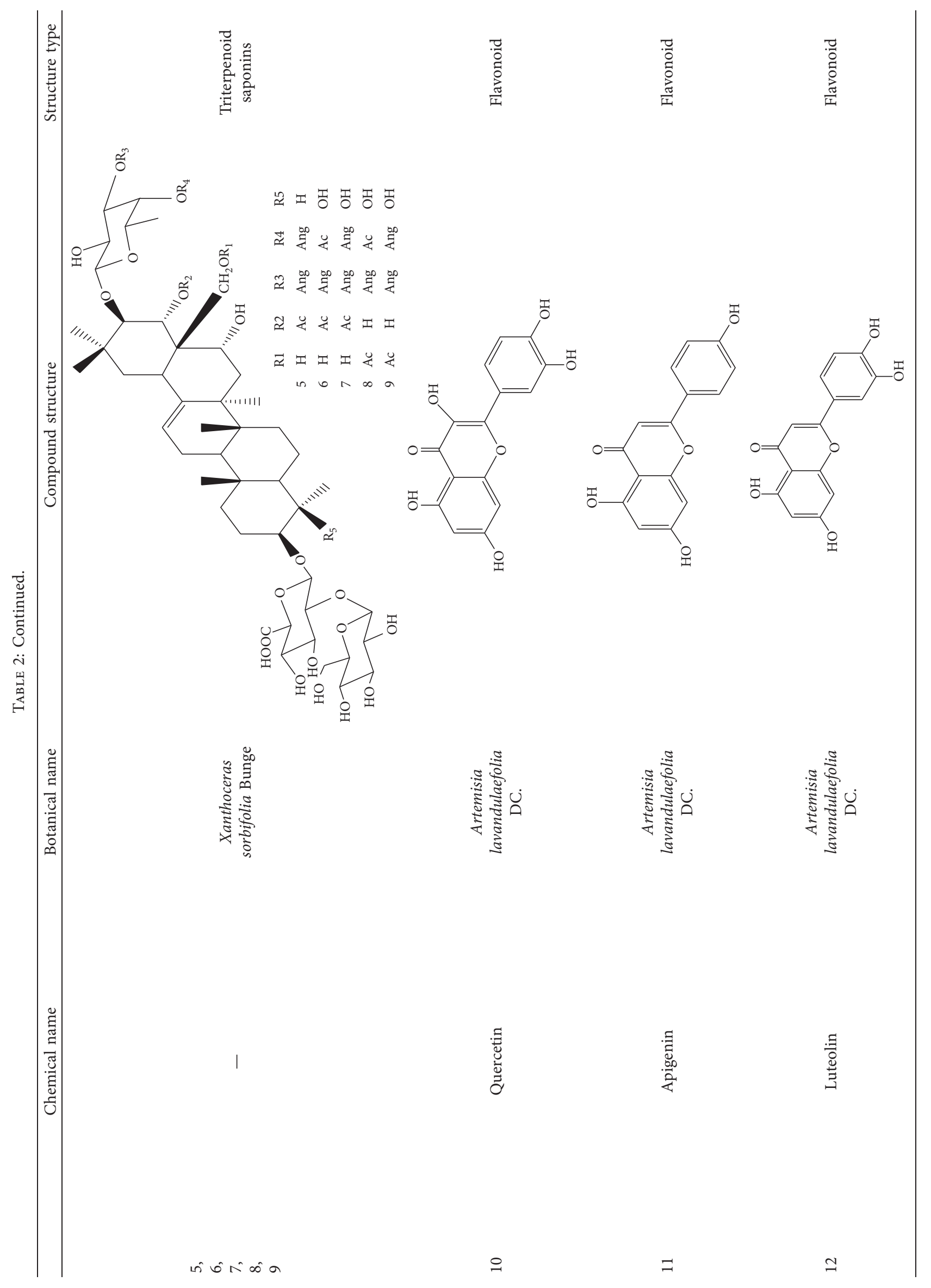




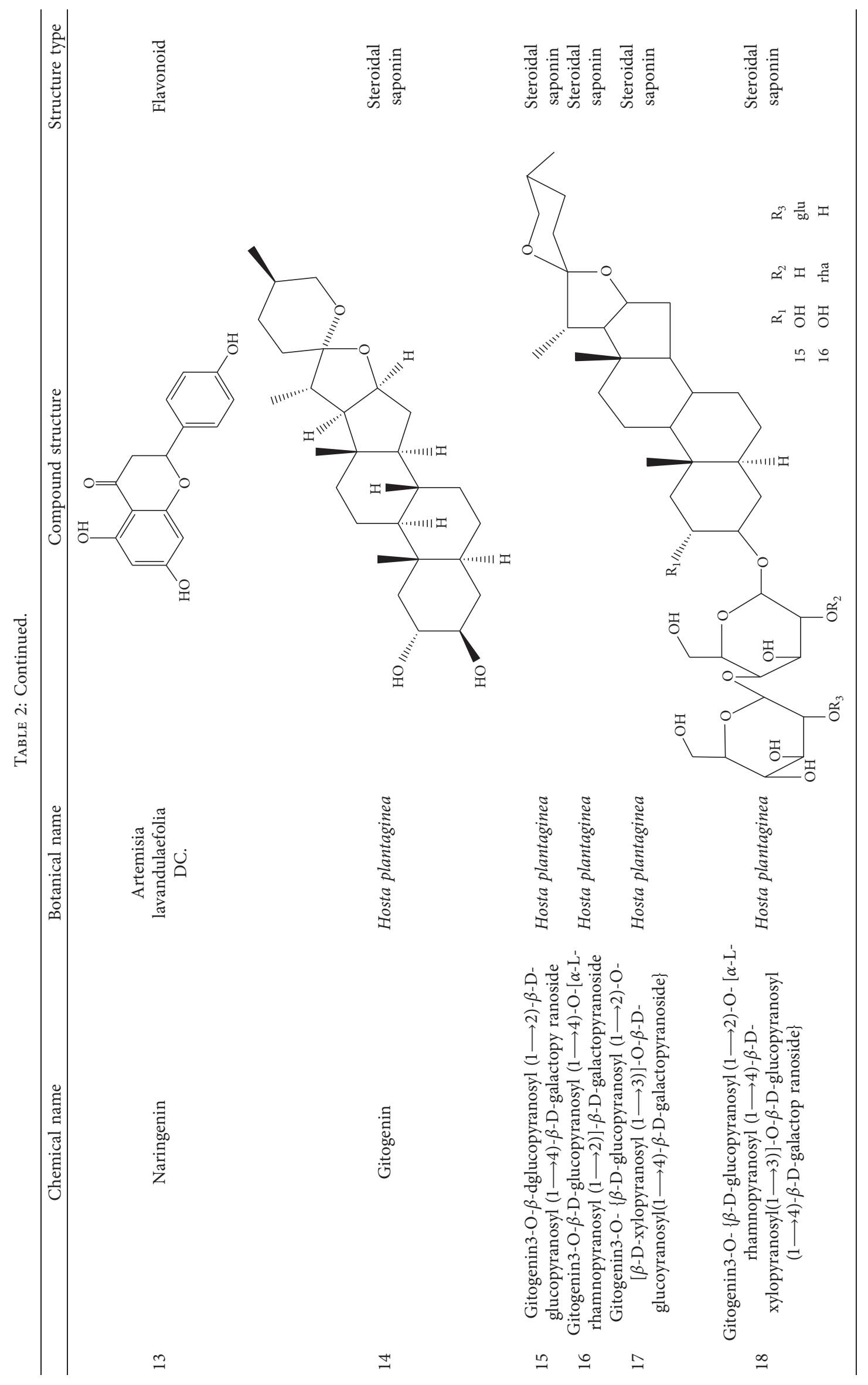




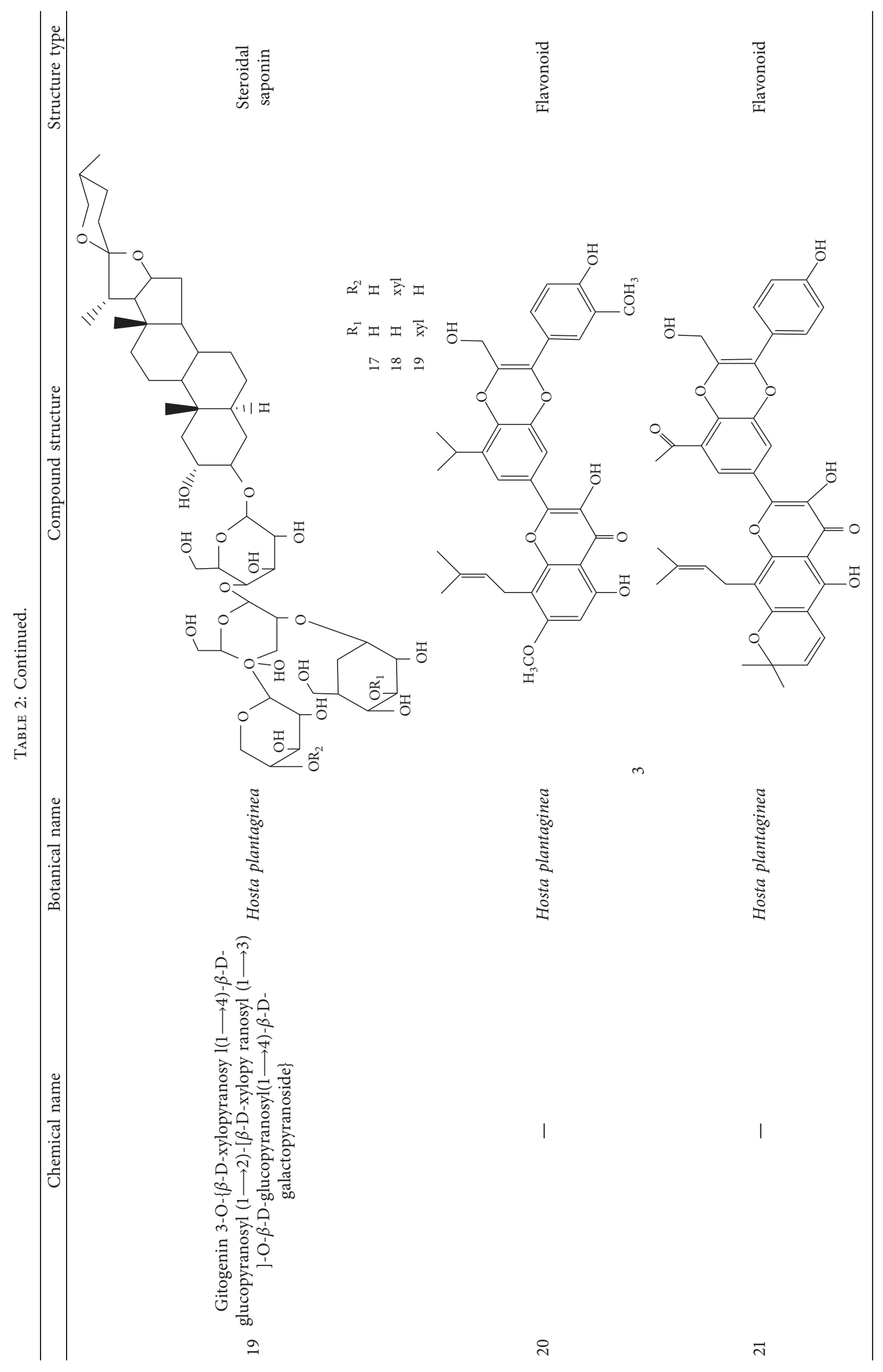




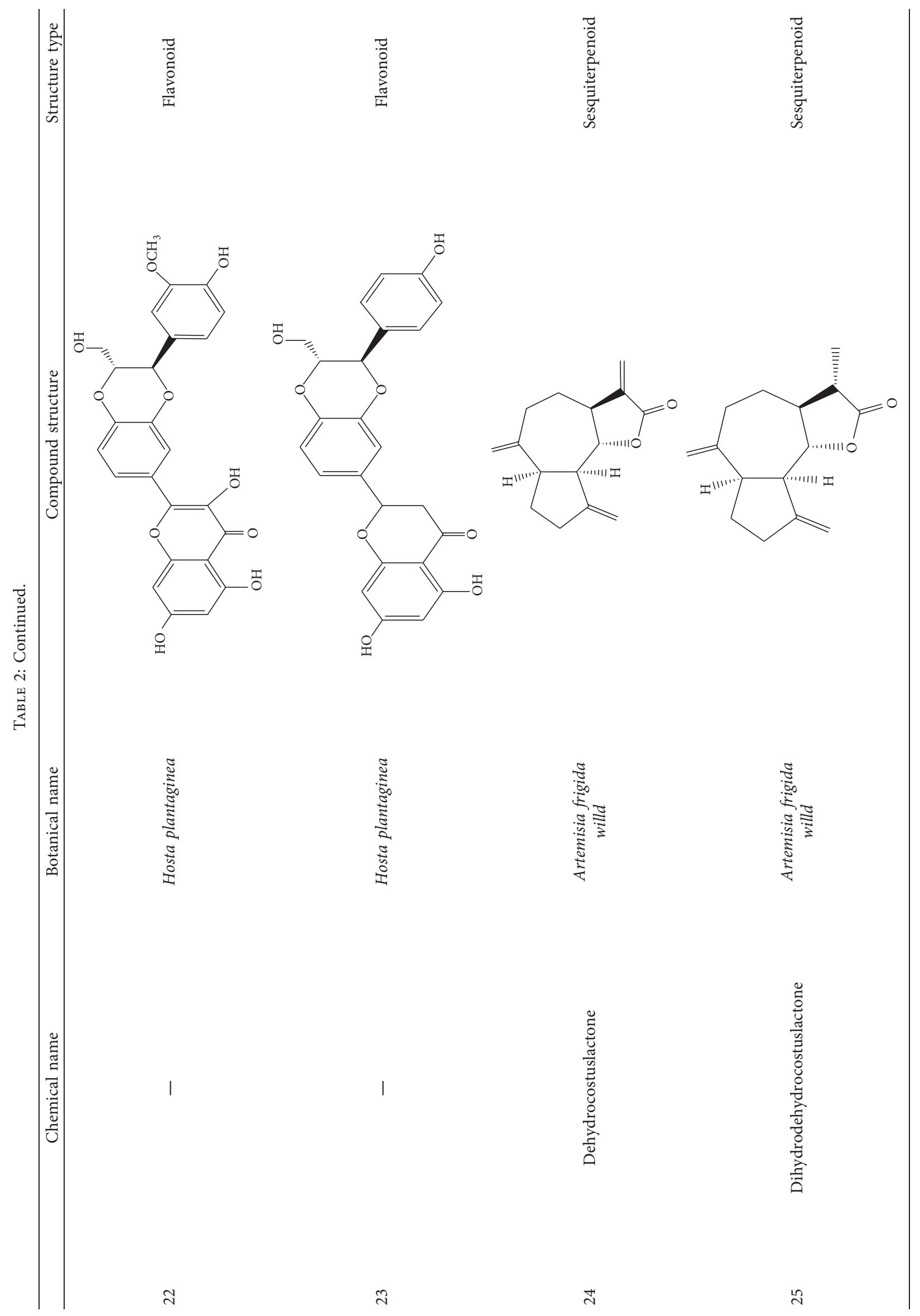




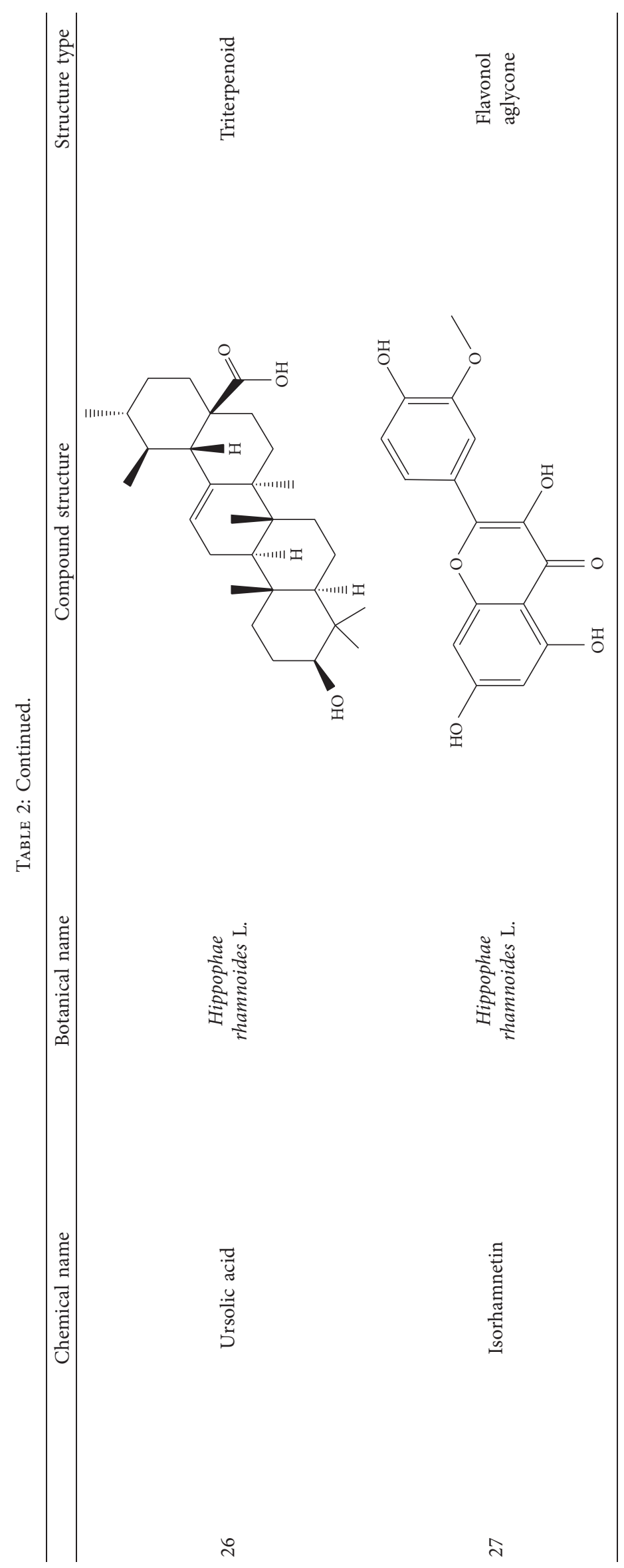




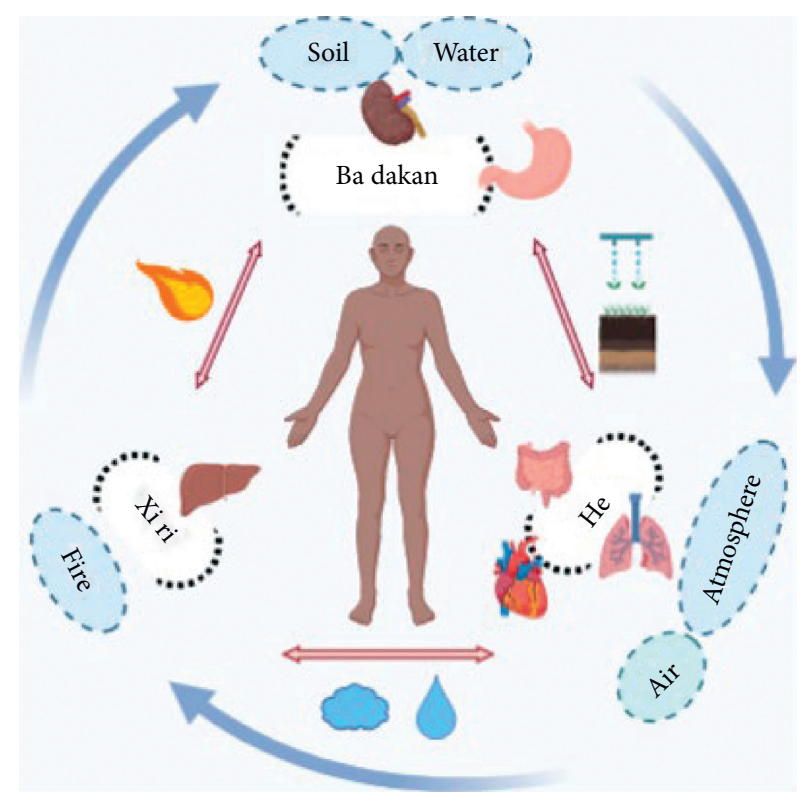

FIgURE 1: The concept of Mongolian medicine in treating diseases.

powder [21] can alleviate the symptoms of $\mathrm{CCl}_{4}$-induced liver fibrosis in rats, which may be due to its ability to downregulate the serum transaminase and coordinate the MMPs/TIMPs system.

3.2. Honghua Qinggan 13 Flavors. Honghua Qinggan 13 flavors (HHQG) is from the Four Medical Tantras and is called "gurigumu-13," which is included in the "Pharmaceutical Standards of the Ministry of Health of the People's Republic of China" (Mongolian Medicines Volume) [41]. It is composed of saffron, clove, lotus seeds, Radix Ophiopogonis, Radix aucklandiae, Melia toosendan, gardenia, lignum pterocarri, musk, pulvis cornus bubali concentratus, calculus bovis, and vermilion and has the efficacy of clearing heat, detoxifying and cooling blood. At present, there are many studies on the liver-protecting pharmacological effects of single drugs in the prescription but few studies on the pharmacological effects and mechanism of the prescription. HHQG can be used to treat liver diseases [41, 42], including liver failure, drug-induced hepatitis, alcoholic liver, fatty liver, etc. [43]. HHQG exhibits a certain therapeutic effect on liver injury and fibrosis of rats caused by $\mathrm{CCl}_{4}$, and the mechanism may be related to the antioxidant effect on regulating the activity of MMP-1 and TIMP-1 [22]. Hepatic fibrosis is the prophase lesion of cirrhosis and the key link in the progression of hepatocellular carcinoma. The anti-inflammation, free radical scavenging, antioxidant, activated HSC apoptosis, immune regulation, antiendotoxin, and other effects of the single drug were analyzed. The main mechanism of its antihepatic fibrosis may be through TGF$1 /$ Smad and NF- $\kappa \mathrm{B}$ signal transduction pathways [23]. Ruimin Li [24] discussed the relationship between hepatitis $B$ virus tumor markers and liver cancer. HHQG can significantly decrease four tumor markers, including fetoprotein (AFP), A-L-fucoidase (AFU), R-glutamate transdermal enzyme (R-GT), and carcinoembryonic antigen (CEA) and reduce $\mathrm{HBV}-\mathrm{DNA}$, which indicates a lower cancer rate.

3.3. Changpu Siwei. Changpu Siwei is composed of Galanga Rhizome, Halitum Purpureum, Vladimiriae Radix, and Acorus gramineus. This prescription has the efficacy of

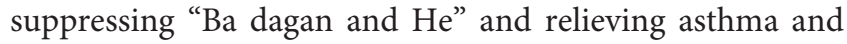
pain, therefore, being used for oppression in the chest, dyspnea, indigestion, asthma, and pain in clinics [44]. In Mongolia, Changpu Siwei is named Shu da ge-4. It is included in the "Pharmaceutical Standards of the Ministry of Health of China (Mongolian Medicine)" [37]. The Ethanol and petroleum ether extracts of Changpusiwei exhibit prominent growth inhibitory effects on SMMC-7721 cells at $12.5 \sim 200 \mathrm{~g} / \mathrm{mL}[25]$.

3.4. Empirical Prescriptions. There are many empirical prescriptions with obvious clinical efficacy [45], such as E ligeng-II, Safflower qinggan 13 flavors, et al. They are effective to treat liver pain and liver enlargement of liver cancer with the function of activating blood circulation, removing blood stasis, and relieving pain [46]. At present, the pharmacological mechanism of most Mongolian prescriptions used in clinics has not been studied. They are used according to pharmacopoeia and physicians' experience. Hepatoprotective Mongolian I and II are two empirical prescriptions commonly used to cure liver cancer.

3.4.1. Hepatoprotective Mongolian I. Hepatoprotective Mongolian I (HM I) is a complex mixture of 18 natural plants in which Terminalia chebula is the main ingredient. Terminalia chebula, due to its complicated components, has a wide range of pharmacological functions, including prevention and treatment of tumors [47]. Researchers [26] have demonstrated that HM I exhibited significant proliferation inhibition on Huh-7 cells and the mechanism involves cell cycle arrest and cell apoptosis promotion. In addition to the growth inhibition effect, the chemotherapy sensitization effect of HM I was also found. These results have great significance for the popularization and application of HM I against liver cancer in clinics.

3.4.2. Hepatoprotective Mongolian II. Hepatoprotective Mongolian prescription II (MPII) consists of 18 medicinal herbs. It has been reported that MPII [27] significantly inhibited the growth of human liver cancer cells Huh-7 and HepG2. At the molecular level, MPII induced cell apoptosis, arrested G0/G1 cell cycle phase, and promoted expressions of caspase-3, caspase-8, caspase-9, and cytochrome $c$ in Huh-7 and HepG2 cells. In vivo, MPII dramatically inhibited human liver cancer growth in a xenograft model in Kunming mice with no apparent cytotoxicity to the hosts. When combined with 5-FU, MPII decreased the toxicity of 5-FU on liver cancer cells. These results have suggested that MPII might have the potential to be a powerful therapy in liver cancer. 


\section{Monomer Compounds and Extracts}

Commonly used medicines for removing stasis and stagnation in Mongolian medicine include Monetariae concha, Concha Mauritiae, Clematis aethusifolia Turcz., Clematis intricata Bunge, Ranunculus sceleratus L., Parnassia palustris L., GnaphaliumaffineD. Don, etc. They are used to treat food stagnation, all kinds of "Pi kuai," carbuncle swelling caused by metabolic disorders, and the accumulation of scum and essence [35]. Here, we summarize the common drugs and monomers for the treatment of liver cancer.

4.1. Terminalia chebula (Terminalia chebula Retz). Terminalia chebula is the dried ripe fruit of Terminalia Chebula Retz. or Terminalia Chebula Retz. var. tomentella Kurt which belongs to the family of Combretaceae $\mathrm{R}$. Br. It is not only used in Mongolian medicine, Chinese medicine, and Tibetan medicine in China but also used in other countries such as India and Iran. It is included in the "pharmacopoeia of the People's Republic of China," which has the efficacy of restraining "Xiri," astringent trauma, promoting tissue regeneration, and assisting digestion, and detoxication [35]. Mongolian doctors believe that Terminalia chebula can cure all kinds of toxicities [48]. Modern pharmacological research has shown that Terminalia chebula can be used for asthma, inflammation, neurological disorders, and wound infection and be frequently used as a part of many preparations to treat a variety of diseases; therefore, it is known as "the king of medicine" [49]. Pentagalloyl glucose (PGG, 1) is a natural polyphenol from Terminalia chebula. It has been reported that PGG has anticancer activity in ovarian cancer and nasopharyngeal carcinoma [50]. Researchers [51] have suggested that PGG can inhibit the proliferation, migration, and invasion of HepG2 cells and induce cell cycle G1 phase arrest and cell apoptosis. The combination of PGG and 5-FU shows a synergistic effect on the reversal of the aggressive phenotypes of HepG2 cells. PGG has the potential to be used to treat liver cancer in clinics. Chebulagic acid (2) is a benzopyran tannin obtained from Terminalia chebula. The combination of Chebulagic acid and doxorubicin shows strong synergism in inhibiting liver cancer cell growth. Furthermore, Chebulagic acid can enhance the sensitivity of HepG2 cells to doxorubicin, thus showing anticancer effects against liver cancer [52]. Chen et al. [53] have found that ethyl acetate extract of Terminalia chebula can mediate the gene expression of Fas/ FasL family through an exogenous pathway, thus inducing the apoptosis of immortalized rat hepatic stellate cells. Reversing liver fibrosis can effectively prevent the development of liver cancer [54]. The ethyl acetate extract of Terminalia chebula can effectively reverse the development of liver fibrosis and, to some extent, prevent liver cancer. The water extract of Terminalia chebula can obviously inhibit the proliferation activity of liver cancer cells [55] (Figure 2).

4.2. Safflower (Carthamus tinctorius L.). Safflower is the dry flower of Compositae Carthamus tinctorius L. The Mongolian medicine canonical "Classic Canon of Mongolian
Materia Medica" [56] has recorded that safflower can remove liver heat, regulate menstruation, detumescence, and stop bleeding. It has long been used in Mongolian medicine and traditional Chinese medicine $[57,58]$. This herbal medicine is clinically compatible with other drugs for the treatment of hepatomegaly, liver damage, and irregular menstruation. Safflower yellow B (SYB, 3) is one of the main bioactive constituents of safflower. Sharula et al. [59] have proposed SYB to be a promising therapeutic compound for liver cancer as they found that SYB inhibited cell proliferation and promoted cell apoptosis mainly through miR-34a/P53/caspase-9 axis in HepG2 cells, demonstrating the clinical application value of SYB in liver cancer treatment.

Hydroxysafflor yellow A (HSYA, 4), a water-soluble chalcone from safflower, is frequently studied previously for its neuroprotective effect in cerebrovascular and neurodegenerative diseases. Recently, the positive action of HSYA in the prevention of liver damage caused by chemicals or alcohol and the anticancer effect of HSYA in various types of cancers are also reported. HSYA inhibited proliferation, migration, and induced apoptosis through suppressing p38MAPK signaling in HepG2 cells [60]. Another research has shown that HSYA induced autophagy by promoting the expression of Beclin 1 and inhibited the phosphorylation of ERK in liver cancer cells [58]. These findings provide experimental evidence that HSYA might be a promising anticancer agent for HCC (Figure 3).

4.3. Xanthoceras sorbifolia Bunge. Xanthoceras sorbifolia Bunge, which belongs to Sapindaceae, has been used as TCM for curing arterial sclerosis, hyperglycemia, hyperpiesia, chronic hepatitis, rheumatism, and enuresis of children $[61,62]$. The chemical constituents and pharmacological activities of its branches, leaves, flowers, stalks, kernels, shells, and wood have been studied by scholars at home and abroad. The wood, branches, and leaves have been used in Mongolian medicine and are thought to have significant effects on drying "Xiri," clearing heat, and relieving swelling and pain. Lili Yu [61] isolated some triterpenoid saponins from the seed oil leavings of X. sorbifolia Bunge and found cytotoxicity of these compounds on several human cancer cell lines. Compounds $5 \quad\left(\mathrm{IC}_{50}=2.45 \pm 0.58 \mu \mathrm{M}\right)$ and 7 $\left(\mathrm{IC}_{50}=4.03 \pm 0.75 \mu \mathrm{M}\right)$ show significant activity against $\mathrm{HepG}_{2}$ cell line, while compounds 6 $\left(\mathrm{IC}_{50}=22.20 \pm 1.92 \mu \mathrm{M}\right), 8 \quad\left(\mathrm{IC}_{50}=60.83 \pm 0.94 \mu \mathrm{M}\right)$ and 9 $\left(\mathrm{IC}_{50}=33.11 \pm 2.21 \mu \mathrm{M}\right)$ exhibit moderate activity against HepG2 cell line (Table 2). Extracts from the X. sorbifolia Bunge exhibit cytotoxicity toward various human cancer cell lines [63, 64]. Meanwhile, TSXS could lead to apoptosis by stimulating the cells to produce oxidative stress (Figure 3). Total saponins from X. sorbifolia Bunge (TSXS) induced apoptosis of HepG2 cells through mitochondria-mediated apoptosis pathway and arrested the cell cycle at the $S$ phase [63]. Polyphenols from the Husks of X.Sorbifolia exhibited anticancer and radical-scavenging effects in several cancer cells [64]. The results of these studies provide a theoretical basis for further development of X. sorbifolia Bunge. 


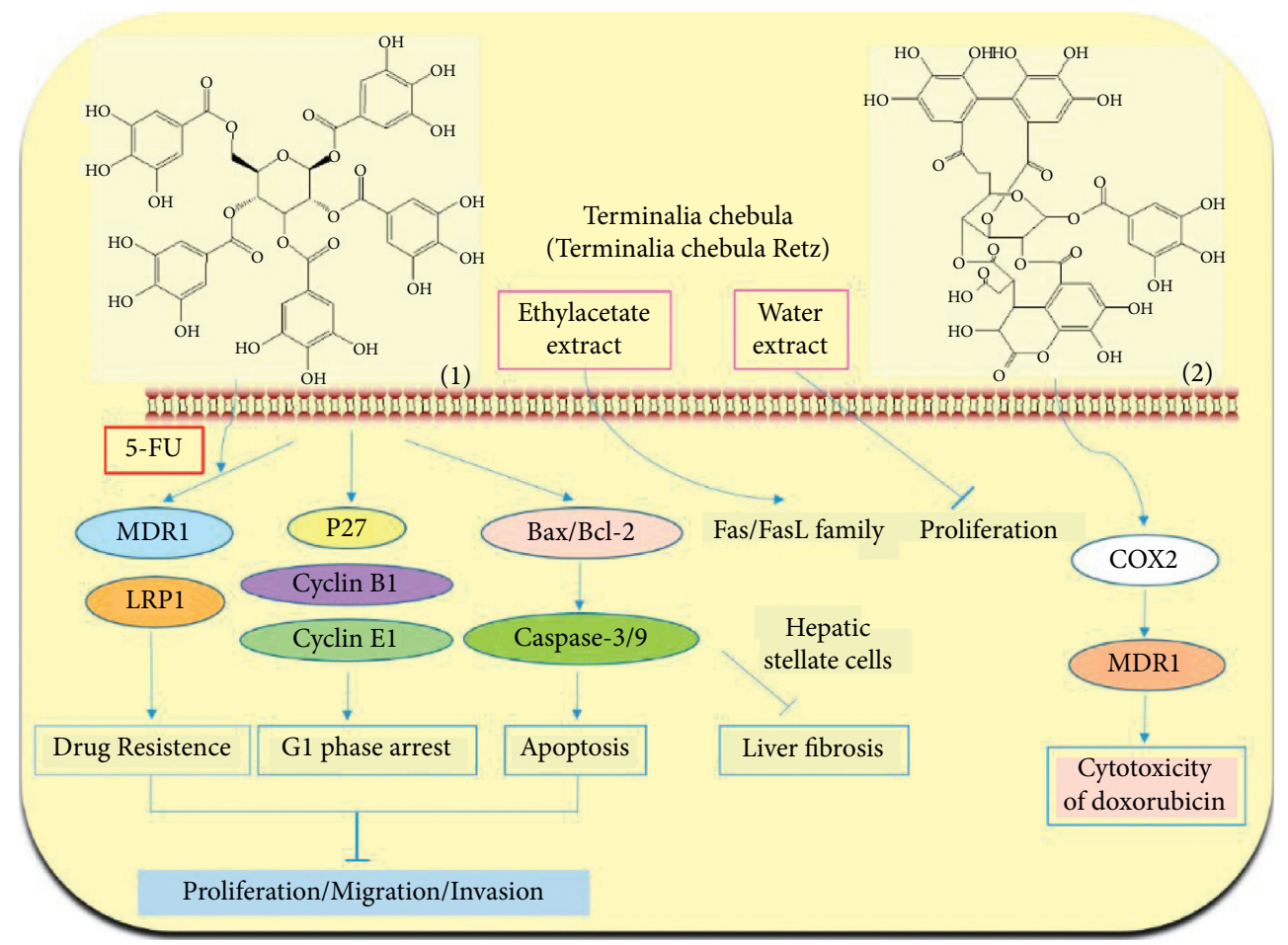

Figure 2: The anticancer mechanism of Terminalia chebula in liver cancer.

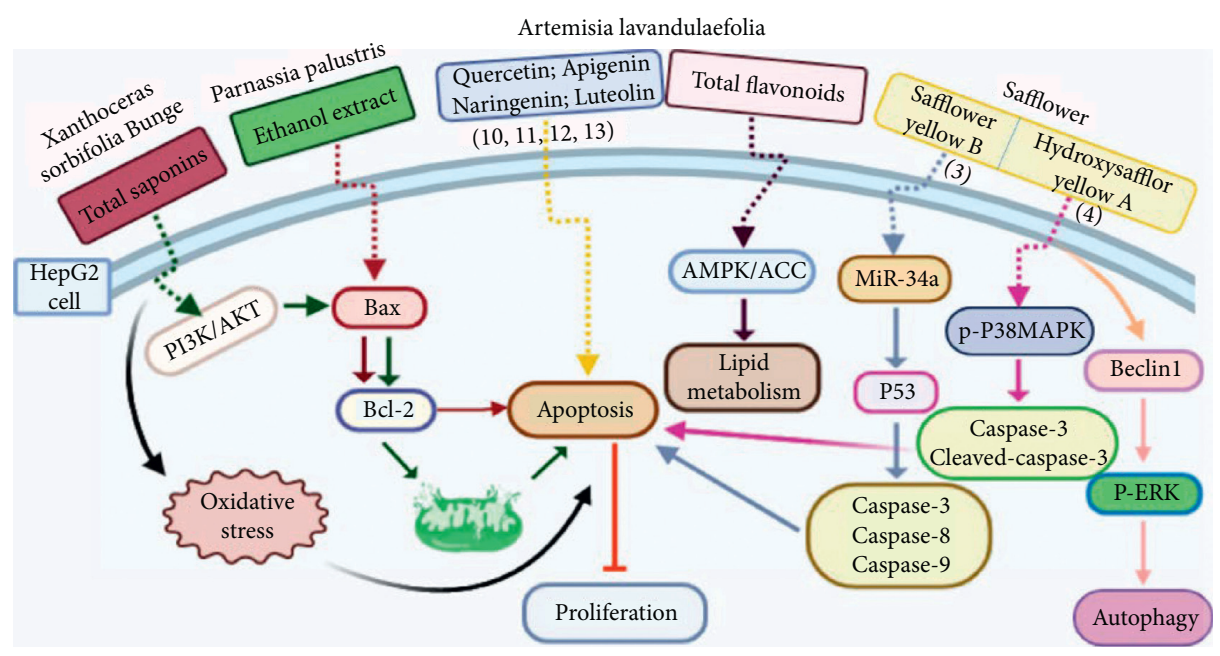

FIGURE 3: The anticancer mechanism of monomer compounds and extracts in liver cancer.

4.4. Parnassia palustris. Parnassia palustris is the whole herb of Parnassia palustris Linn. It is commonly used for clearing heat, detoxifying, reducing swelling and eliminating abscess during the treatment of various diseases, such as Jaundice hepatitis, laryngitis, mumps, vasculitis, tuberculosis, and cancers $[65,66]$. It has been demonstrated that the ethanol extract of Parnassia palustris significantly inhibited the proliferation of HepG2 cells and, by detecting apoptosisrelated proteins, the underlined mechanism might involve apoptosis promotion [67, 68] (Figure 3).

\subsection{Artemisia lavandulaefolia DC}

Artemisia lavandulaefolia DC. is used in traditional Mongolian medicine as a perennial herb that is widely distributed in Inner Mongolia of China. It is a member of Artemisia compositae, with expelling cold, clearing damp, warming, and activating meridian, halting bleeding, antibacteria, antiallergy, anticancer effects, and it is commonly used in formulae, such as TGLG-1 $[69,70]$. Modern pharmacology research has shown that 
extracts and compounds from A. lavandulaefolia exhibited potential anticancer activities. Quercetin (10) and apigenin (11) which are isolated from A. lavandulaefolia [71] displayed apoptosis promotion effect in HepG2 cells. Meanwhile, four kinds of flavonoid glycosides, including luteolin (12), naringenin (13), quercetin, and apigenin, from A. lavandulaefolia could inhibit the proliferation of HepG2 cells [72]. The total flavonoids of A. lavandulaefolia activated the AMPKACC pathway in HepG2 cells, therefore participating in the lipid metabolism of HepG2 cells [73] (Figure 3).

4.6. Flowers of Hosta plantaginea. Hosta is a genus of the Liliaceae family. There are four primitive species in China, $H$. plantaginea, $H$. ventricosa, $H$. ensata, and white $H$. albofarinosa [74]. H. plantaginea is a landscaping plant and an annual herb widely distributed in temperate and subtropical Asia, including China, Japan, North Korea, and the far east of Russia, mostly cultivated. The dried flowers of Hosta plantaginea as Mongolian medicine were documented in "Chinese Materia Medica Mongolian medicine roll." It possesses diuresis detumescence, heat-clearing, and detoxicating, hemostasis, and anti-inflammatory effects [48]. $H$. ventricosa was also recorded in "Chinese Materia Medica Mongolian medicine roll," with cooling blood and hemostasis and detoxicating effects. The whole plant of $H$. ventricosa is used as medicine [37]. Studies [75] have indicated that the total saponins of $H$. ventricosa (TSHV) could effectively inhibit the proliferation of HepG2 cells in vitro with an $\mathrm{IC}_{50}$ value as $17.37 \mu \mathrm{g} / \mathrm{L}$. Pharmacological and chemical studies on $H$. plantaginea have suggested that the alcohol extract and some compounds showed antibacterial [76], ant-fungal [77], anti-inflammatory [78, 79], analgesic [80], and anticancer effects [78], etc. The cytotoxic effect of four monomer compounds isolated from the flowers of $H$. plantaginea has been studied [81]. Among these compounds, compound Gitogenin (14) selectively inhibited the proliferation of cancer cells, including K562, YAC-1 and SMMC-7721 cell lines, and the $\mathrm{IC}_{50}$ of compound (14) in SMMC-7721 is $2.84 \mu \mathrm{g} / \mathrm{ml}$. The steroidal saponins of $H$. plantaginea showed cytotoxicity on various cancer cell lines and these anticancer effects are cell type dependent [82]. Compounds (15), (16), (17), (18), and (19) displayed strong inhibitory effects on human liver cancer cells (HepG2) with $\mathrm{IC}_{50}$ values ranging from $0.16 \mathrm{~mol} / \mathrm{L}$ to $1.16 \mathrm{~mol} / \mathrm{L}$, which are equivalent to or stronger than the effect of cisplatin, a positive drug in the experiment. Wei et al. [83] isolated and identified some flavonoids from $H$. plantaginea (Lam.) Aschers. They examined the hepatoprotective activity of these flavonoids on $\mathrm{CCl}_{4}$-induced injury of human L-O2 cells and found that compounds (20), (21), (22), and (23) exhibited moderate hepatoprotective activities.

4.7. Artemisia frigida Willd. Artemisia frigida belongs to Artemisia (Compositae). It has been used for hundreds of years as a Mongolian traditional herbal medicine which is widely distributed in the Inner Mongolia Autonomous
Region of China [84]. It is also named Xiaobaihao or Hanhao in Chinese and "Agi" in Mongolian. After flowering, the aboveground part of $A$. frigida is harvested, dried in the shade, and ground into powder. It is used for the treatment of various bleeding, kidney fever, irregular menstruation, sores, and Carbuncle pains [85, 86]. Researchers [87] have found five sesquiterpenoids from A. frigida and these compounds exhibited obvious inhibitory effects on human cancer cells. One of the compounds, dehydrocostuslactone (24) exhibited significant inhibition in HLE cells with the $\mathrm{IC}_{50}$ of $22.50 \mu \mathrm{M} / \mathrm{L}$. Dihydrodehydrocostuslactone (25) possessed moderate inhibition in human cancer cells only in high concentration treatment. Unsaturated lactone is the essential functional group of sesquiterpene lactones which inhibited the proliferation of cancer cells.

4.8. Sea Buckthorn (Hippophae rhamnoides L.). Sea buckthorn is the fruit of Hippophae rhamnoides L. which is a wild berry plant characterized by multiple economic advantages and versatile properties. H. rhamnoides L. is a kind of "medicine and food homologous" plant with high utilization value. Sea buckthorn is commonly used in Mongolian medicine to cure cough, sputum, pulmonary tuberculosis, pulmonary abscess, and lung cancer according to its effects of relieving cough, eliminating phlegm, suppressing "Badakan," and promoting digestion. Sea buckthorn consists of more than 100 kinds of bioactive compounds, including essential amino acids, vitamins, trace elements, tocopherols, carotenoids, polyphenols, flavones, and other active substances [48, 88]. Ursolic acid (26), extracted from H. rhamnoides L., has been reported to increase IL-12 and TNF- $\alpha$ [89], activate cell immunity, and further inhibit angiogenesis, finally showing anticancer effect against liver cancer in vivo. Grey et al. [90] have performed a sequential extraction and found that ethanol: water extract of sea buckthorn exerted the strongest proliferation inhibitory effect in HepG2 cells. The $80 \%$ ethanol reflux extracts of sea buckthorn fruit, stem, and leaf showed different degrees of anticancer effect on mouse hepatocellular carcinoma H22 tumor strains [91]. Flavonoids from oil-removed seeds of H. rhamnoides (FSH) could inhibit cell proliferation and induce cell apoptosis in a dose-dependent manner $(200 \sim 1200 \mu \mathrm{g} / \mathrm{mL})$ in BEL-7402 cells [92]. Isorhamnetin (27), a flavonol aglycone, was isolated from $H$. rhamnoides L. and showed cytotoxicity on BEL-7402 cells dose- and time-dependently, with $\mathrm{IC}_{50}$ of $74.4 \pm 1.13 \mu \mathrm{g} / \mathrm{ml}$ [93]. The mechanism of this cytotoxicity in response to isorhamnetin $(50 \mu \mathrm{g} / \mathrm{ml}, 48 \mathrm{~h})$ might involve its apoptosis promotion effect (Figure 4).

\section{Discussion}

Currently, the progress of liver cancer clinical treatment has been few and far between. Due to the rapid development of the disease, most of the patients are in the middle and late stage or even have metastases at the time of clinical diagnosis and could not be treated with radical resection [94]. 


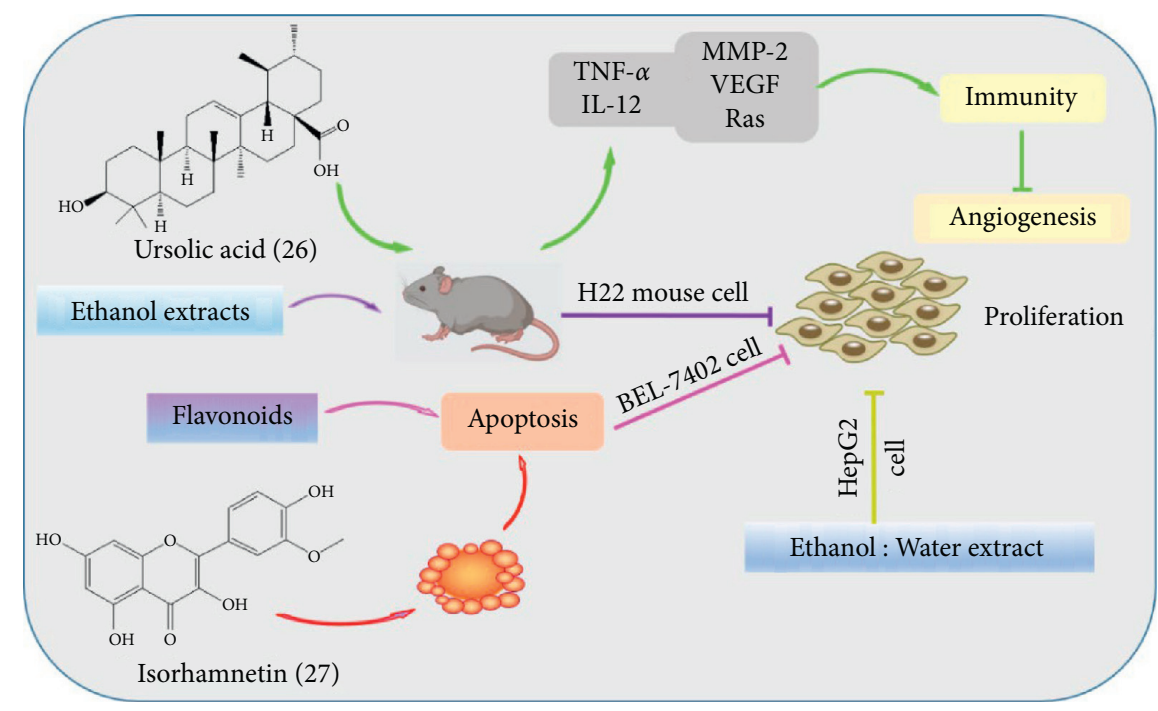

Figure 4: The anticancer mechanism of Sea buckthorn in liver cancer.

Therefore, it is urgent to find more promising treatment strategies.

Mongolian medicine is not only an important part of Chinese traditional medicine but also a treasure of Chinese traditional culture and national intangible cultural heritage. It has important medicinal and academic value. The main drugs (prescriptions) used in the treatment of tumors in Mongolian medicine contain ruyijiedu pill, jisiwunisi-25 pill, hualiu pill, Zhuangxi Power, gamujur, habuder-9 powder, susi-12 powder, etc. Naren mandu la -11 $[95,96]$ and Aili gen-II are clinical prescriptions commonly used to treat liver cancer and have been proved to be effective in liver cancer therapy. Notably, the research on Mongolian medicine mostly stays at the original treatment level, while the research on the underling mechanism is relatively less. Most of the studies focus on the anticancer activities of monomer compounds obtained from Traditional Mongolian Medicine. However, studies on the activity and mechanism of formulae are few. Furthermore, most experiments evaluating anticancer mechanism of Traditional Mongolian Medicine are just conducted on cancer cell models in vitro. The proofs in vivo are limited [6]. At present, the bottleneck in the development of Mongolian medicine lies in the fact that Mongolian medicine is not well known by the vast majority of people in China so it just plays roles in a relatively small scope. Therefore, further in-depth research of the anticancer mechanism of Mongolian medicine in liver cancer and close combination of the basic research with clinical application is urgently required.

\section{Conclusions}

Mongolian medicine has been used for a long history to prevent or treat various diseases, including liver cancer. It shows mild and lasting pharmacological effects with multiple advantages: amelioration of sensory symptoms, improvement of the quality of life, prolongation of overall survival and, to some extent, low side effects. This review provides a comprehensive summary of Traditional Mongolian Medicine, with the purpose of finding promising drugs to treat liver cancer and expanding the clinical application of Traditional Mongolian Medicine in liver cancer therapy.

\section{Data Availability}

All data used to support the findings of this study are included within the article.

\section{Disclosure}

Xiaomei Bao and Lu Chen share first authorship.

\section{Conflicts of Interest}

The authors declare no conflicts of interest.

\section{Authors' Contributions}

Xiaomei Bao and Lu Chen have contributed equally to this work. YQ contributed to conception and design. $\mathrm{XB}$ searched the literature. XB, LC, and YQ wrote the manuscript. YL, HS, KW, YL, TQ, and YL drafted and critically revised the work. All authors read and approved the final manuscript.

\section{Acknowledgments}

This work was supported by grants from the National Natural Science Foundation of China (no. 81973570 to Y. Qiu), and the authors thank the same.

\section{References}

[1] H.-Y. Lee and I.-S. Hong, "Targeting liver cancer stem cells: an alternative therapeutic approach for liver Cancer," Cancers, vol. 12, no. 10, p. 2746, 2020. 
[2] S. K. Asrani, J. Mellinger, J. P. Arab, and V. H. Shah, "Reducing the global burden of alcohol-associated liver disease: a blueprint for action," Hepatology, vol. 73, no. 5, pp. 20392050, 2020.

[3] S. Maruta, S. Ogasawara, Y. Ooka, M. Obu, and N. Kato, "Potential of lenvatinib for an expanded indication from the reflect trial in patients with advanced hepatocellular carcinoma," Liver Cancer, vol. 9, no. 4, pp. 1-15, 2020.

[4] T. F. Greten, C. W. Lai, G. Li, and K. F. Staveley-O'Carroll, "Targeted and immune-based therapies for hepatocellular carcinoma," Gastroenterology, vol. 156, no. 2, pp. 510-524, 2019.

[5] Z. Zhu, T. Wang, D. Fu, Y. Gui, J. Wang, and T. Cui, "Innovative development path of ethnomedicines: an overview of ethnomedicines in China," Frontiers of Medicine, vol. 10, no. 2, pp. 166-177, 2016.

[6] H. S. Peng, L. P. Cha, S. Y. Gui et al., "Current situation and Thinking of basic research and discipline construction of Mongolian medicine," Bulletin of National Natural Science Foundation of China, vol. 09, no. 03, pp. 1-8, 2020.

[7] Y. F. Xiao, F. H. Chang, X. Y. Qian, N. Wang, and Y. Q. Han, Present Situation and Development of Mongolian Medicine, pp. 93-98, Chinese Society of Toxicology, Hangzhou, China, 2019.

[8] Y. M. Qiao, A Comparative Study of Chinese and Mongolian Medicine, Beijing University of Chinese Medicine, Beijing, China, 2013.

[9] H. Y. Tong, X. H. Bai, and X. M. Gao, "Comparative researches on the application of Chinese medicine and Mongolian medicine," China Journal of Traditional Chinese Medicine and Pharmacology, vol. 11, pp. 1018-1021, 2008.

[10] C. H. Zhang, D. Man, G. D. Wu et al., "Protection, exploitation and utilization states of specialized Mongolian folk medicine resources and related development strategy," China Journal of Chinese Materia Medica, vol. 40, no. 05, pp. 771777, 2015.

[11] C. X. Liang, "On the compiling and editing features and significance of Tibetan medical classic "the four medical classics", Journal of Minzu University of China (Philosophy and Social Sciences Edition), vol. 37, no. 02, pp. 108-112, 2010.

[12] W. qimuge and Qiqige, "Brief introduction to the historical origin of Mongolian medicine," Journal of Medicine \& Pharmacy of Chinese Minorities, vol. 18, no. 12, pp. 60-62, 2012.

[13] C. M. Bai and S. H. Shi, "On the formation, development and prospect of Mongolian medicine," Journal of Medicine \& Mharmacy of Chinese Minorities, vol. 04, pp. 43-44, 2004.

[14] H. S. Bao, "Jambaldorj and research on herbal medicines in the classic Canon of Mongolian Materia Medica," Journal of Traditional Chinese Medical Literature, vol. 28, no. 01, pp. 24-26, 2010.

[15] H. S. Bao, "On contribution of Jambaldorj to the development of Mongolian medicine," Chinese journal of medical history, vol. 01, pp. 29-32, 2010.

[16] C. H. Liu, W. Z. Hu, Y. B. He, A. L. Jiang, and G. K. Xu, "Development history and research progress on Mongolian Medicine," Journal of Anhui Agriculture Science, vol. 40, no. 22, pp. 11476-11478, 2012.

[17] B. Khandarmaa, Literature Research on the Influence of Traditional Mongolian Medicine Bloodletting Therapy in the "The Four Medical Tantras", Beijing University of Chinese Medicine, Beijing, China, 2020.

[18] Q. Q. Chen, "Research on the medical exchange between han people and Tibetan people in ancient times," Chinese Medicine and Culture, vol. 15, no. 04, pp. 61-69, 2020.
[19] H. Y. Ge and J. Hao, "Effect of Qinggan Jiuwei san, a Mongolia herbal medicine,on serum TIMP-1 levels in treatment of patients with alcoholic hepatitis," Journal Practice Hepatology, vol. 19, no. 06, pp. 720-721, 2016.

[20] H. Y. Ge, S. H. Zhang, B. S. Zhao, and C. K. Yu, "Clinical effect of Mongolian medicine Qinggan Jiuwei powder in treatment of alcoholic liver fibrosis," Journal Clinical Hepatology, vol. 33, no. 12, pp. 2316-2320, 2019.

[21] H. Y. Ge, A. Q. Wang, L. Gao, and Y. X. Li, "Effects and mechanisms of Qinggan jiuwei powder on the liver fibrosis in rats," Chinese Journal of Clinical Pharmacology, vol. 35, no. 22, pp. 2859-2862, 2019.

[22] T. Bao, "Research Progress on mechanisms of Honghua Qinggan 13 flavors for primary liver cancer and its metastasis," Chinese Community Doctors, vol. 34 , no. 36, p. $8+10$, 2018.

[23] T. Bao, "Study on the mechanism of Mongolian medicine honghua-13 in treating hepatic fibrosis," World Latest Medicine Information (Electronic Version), vol. 18, no. 80, pp. 239-240, 2018.

[24] R. M. Li and J. B. Liu, "Effect of Honghua Qinggan-13 on tumor markers of liver cancer," Journal of Medical Forum, vol. 03 , p. 79+81, 2007.

[25] L. L. Bao, Y. X. Wang, J. Q. Bao, X. Jia, and Y. Dong, "Study the effect of Mongolian medicine Changpusiwei on human hepatoma cells in vitro," Journal of Inner Mongolia Medical University, vol. 33, no. 06, pp. 495-498, 2011.

[26] A. Nanda, S. Qimuge, J. R. Bao, and X. L. Su, "Study on the role and mechanism of Hepatoprotective Mongolian I on hepatocellular carcinoma Huh-7 cells," China Medical Herald, vol. 12, no. 35, pp. 26-30, 2015.

[27] A. Nanda, Q. Suyila, L. Xian, and S. Xiulan, "Hepatoprotective Mongolian prescription II enhances the antitumor effects of chemotherapeutics in hepatocellular carcinoma xenografts," Pathology, Research \& Practice, vol. 213, no. 5, pp. 531-540, 2017.

[28] L. W. Han, "Characteristics and innovation in projects of ethnomedicine and ethnopharmacology funded by National Natural Science Foundation of China," China Journal of Chinese Materia Medica, vol. 40, no. 17, pp. 3379-3384, 2015.

[29] G. B. Zhu, "The practical significance of developing Chinese national medicine," Shanghai Journal of Traditional Chinese Medicine, vol. 35, no. 10, pp. 4-6, 2001.

[30] J. Mude, Basic Theory of Mongolian Medicine", Inner Mongolia University Press, Hohhot, China, 3rd edition, 2014.

[31] L. Y. Wu and L. Guo, "Understanding of the holism theory in both of TCM and Mongolian medicine," Chinese Journal Traditional Chinese Medicine Pharmacology, vol. 33, no. 12, pp. 5412-5414, 2018.

[32] A. Gl, "Unique Mongolian medicine," China news of traditional Chinese medicine, vol. 09, no. 14, 2015.

[33] X. H. Zhu, L. T. Yi, and M. H. Li, "Status analysis and strategic thinking on Mongolian medicine standardization," China Journal of Chinese Materia Medica, vol. 33, no. 12, pp. 5412-5414, 2018.

[34] Yu Tuo, Y. Gongbu, The Four Medical Tantras, The Tibet People's Publishing House, Lhasa, China, 1982.

[35] S. Zhabu and S. Bilige, Encyclopedia of Chinese MedicineMongolian Medicine, Science and Technology Press, Shanghai, China, 1992.

[36] A. Gula, Traditional Therapy and Modern Research of Mongolian Medicine, Inner Mongolia People's Publishing House, Hohhot, China, 2006. 
[37] National Pharmacopoeia Committee of People's Republic of China, Drug Standard of the Ministry of Health of the People's Republic of China (Mongolian Medicine Volume), People's Medical Publishing House, Beijing, China, 1998.

[38] Ba Gena, Mongolian Medicine Prescription, Inner Mongolia People's Publishing House, Hohhot, China, 2007.

[39] S. D. Minicis, M. Marzioni, A. Benedetti, and G. Svegliatibaroni, "New insights in hepatocellular carcinoma: from bench to bedside," Annals of Translational Medicine, vol. 1, no. 2, 2013.

[40] X. B. Chen, "Changes in expression of MMP-1 and its inhibitor TIMP-1 in rat hepatic fibrosis," Chinese Journal of Histochemistry and Cytochemistry, vol. 21, no. 03, pp. 274278, 2012.

[41] Pharmacopoeia Committee of the Ministry of Public Health, Pharmaceutical Standards of the Ministry of Health, PRC (Mongolian Medicine), People's Medical Publishing House, Beijing, China, 1998.

[42] China Inner Mongolia Autonomous Region Food and Drug Administration (NMFDA), Drug Instructions of Honghua Qinggan 13 Flavors, Inner Mongolia, China, 1998.

[43] H. X. Yang, Y. F. Bai, L. Chang et al., "The effect of honghuaqinggan-13 on liver injury fibrosis induced by $\mathrm{CCl}_{4}$ in rats," Northwest Pharmaceutical Journal, vol. 33, no. 03, pp. 349-352, 2018.

[44] X. L. Zhu, F. Bai, B. X. Li, J. Xu, and Y. Dong, "Study on anticancer mechanism of Mongolian medicine Shudage-4 based on network pharmacology," Chinese Journal of Traditional Chinese Medicine Pharmacology, vol. 35, no. 07, pp. 3618-3622, 2020.

[45] O. urigi, Traditional Mongolian Medicine and Prescription, Inner Mongolia Science and Technology Press, Chi feng, China, 2013.

[46] A. latengtuya and Sa erna, "Clinical observation of Mongolian medicine in the treatment of primary liver cancer," Chinese Medicine Modern Distance Education of China, vol. 5, no. 8, pp. 24-25, 2006.

[47] B. Anwesa, S. K. Bhattacharyya, and R. R. Chattopadhyay, "The development of Terminalia chebuLa Retz (Combretacae) in clinical research," Asian Pacific Journal of Tropical Biomedicine, vol. 3, no. 3, pp. 244-252, 2013.

[48] National Administration of Traditional Chinese Medicine, Chinese Materia Medica, Mongolian Medicine, Shanghai Science and Technology Press, Shanghai, China, 3rd edition, 2009.

[49] U. Pingali, D. Sukumaran, and C. Nutalapati, "Effect of an aqueous extract of Terminalia chebula on endothelial dysfunction, systemic inflammation, and lipid profile in type 2 diabetes mellitus: a randomized double-blind, placebo-controlled clinical study," Phytotherapy Research, vol. 34, no. 12, pp. 3226-3235, 2020.

[50] D. Y. Shi, X. B. Jin, H. F. Mei, M. Y. Liu, and J. Y. Zhu, "Effect of pentagalloylglucose on expression of apoptosis regulator genes and caspase-dependent apoptosis pathways in HO-8910 cells," Chinese Journal of Pharmacology and Toxicology, vol. 26, no. 04, pp. 534-539, 2018.

[51] X. Q. Ding, S. Zhao, J. Y. Wang, H. C. Zheng, and C. M. Ma, "Inhibitory effects and molecular mechanisms of pentagalloyl glucose in combination with 5-FU on aggressive phenotypes of HepG2 cells," Natural Product Research, vol. 10, no. 04, pp. 1-4, 2019.

[52] C. Achari, G. V. Reddy, T. C. M. Reddy, and P. Reddanna, "Chebulagic acid synergizes the cytotoxicity of Doxorubicin in human hepatocellular carcinoma through Cox-2 dependant modulation of MDR-1," Medicinal Chemistry, vol. 7, no. 5, pp. 432-442, 2011.

[53] Y.-X. Chen, J. Tong, L.-L. Ge, B.-X. Ma, J.-S. He, and Y.-W. Wang, "Ethyl acetate fraction of Terminalia bellirica fruit inhibits rat hepatic stellate cell proliferation and induces apoptosis," Industrial Crops and Products, vol. 76, pp. 364373, 2015

[54] Q. Wang, Y. Zhu, F. X. Long et al., "Advances in animal models of precancerous liver cancer," Hunan Journal of Traditional Chinese Medicine, vol. 33, no. 8, pp. 212-214, 2017.

[55] Z. Q. Bao, The Inhibition of Lung Cancer and Liver Cancer Cells and Ascites Tumor Cells by Terminalia Chebula Water Extract, Inner Mongolia Medical University, Hohhot, China, 2011.

[56] Jambaldorj, The Mongolian Medicine Canonical, Inner Mongolia People's Publishing House, Hohhot, China, 2006.

[57] T. Yamazaki, A. Nakamori, E. Sasaki, S. Wada, and O. Ezaki, "Fish oil prevents sucrose-induced fatty liver but exacerbates high-safflower oil-induced fatty liver in ddy mice," Hepatology, vol. 46, no. 6, pp. 1779-1790, 2010.

[58] Z. Chen, L. Liu, Y. Liu et al., "Hydroxysafflor yellow A induces autophagy in human liver cancer cells by regulating Beclin 1 and ERK expression," Experimental and Therapeutic Medicine, vol. 19, no. 4, pp. 2989-2996, 2020.

[59] S. Sharula and Z. J. Wu, "Regulation of apoptosis by SYB in HepG2 liver cancer cells is mediated by the P53/caspase 9 Axis," Anti-Cancer Agents in Medicinal Chemistry, vol. 17, no. 7, pp. 941-947, 2017.

[60] J. Zhang, J. Li, H. Song, Y. Xiong, D. Liu, and X. Bai, "Hydroxysafflor yellow A suppresses angiogenesis of hepatocellular carcinoma through inhibition of p38 MAPK phosphorylation," Biomedicine \& Pharmacotherapy, vol. 109, pp. 806-814, 2019.

[61] L. Yu, X. Wang, X. Wei et al., "Triterpenoid saponins from Xanthoceras sorbifolia Bunge and their inhibitory activity on human cancer cell lines," Bioorganic \& Medicinal Chemistry Letters, vol. 22, no. 16, pp. 5232-5238, 2012.

[62] B. Luo, F. Cheng, F. L. Li, and K. Zou, "Studies on the chemical constituents of the spermoderm of Xanthoceras sorbifolia Bunge," Lishizhen Medicine and Materia Medica Research, vol. 06, pp. 1329-1330, 2007.

[63] Z. Y. Zhang, Effect and Molecule Mechanism of Total Saponins from Xanthoceras Sorbifolia Bunge Kernel on Apoptosis in HepG2 Hepatoma Cells, Shanxi Normal University, Nanchang, China, 2017.

[64] C.-Y. Yang, W. Ha, Y. Lin, K. Jiang, J.-L. Yang, and Y.-P. Shi, "Polyphenols isolated from Xanthoceras sorbifolia Husks and their anti-tumor and radical-scavenging activities," Molecules, vol. 21, no. 12, p. 1694, 2016.

[65] B. Luo, Mongolian Pharmacy, pp. 459-460, The Ethnic Publishing House, Beijing, China, 1989.

[66] O. urigi and B. Bater, Traditional Mongolian Medicine and Prescription, Inner Mongolia Science and Technology Press, Hohhot, China, 2013.

[67] Y. Hong, L. Da, and Y. Xin, "Study on the effect of ethanol extract of Mongolian medicine Parnassia palustris on the proliferation of hepatocellular carcinoma cells," Journal of Medicine \& Pharmacy of Chinese Minorities, vol. 22, no. 10, pp. 63-65, 2016.

[68] X. Y. Wang, "The study of Proliferation inhibition effects of ethanol extract of Mongolian medicine Parnassia palustris on human liver cancer(HepG2) cells in vitro," World Latest Medicine Information, vol. 17, no. 90, p. 48, 2017. 
[69] C. J. Zhou, Y. L. He, L. S. Zhou, Z. Y. Zhang, and G. Wu, "Effects of four extracts from Mongolia drug TGLG-1 on expression of low density lipoprotein receptor gene in rat hepatocyte strain BRL," Chinese Journal of Modern Applied Pharmacy, vol. 25, no. 3, pp. 186-189, 2008.

[70] G. Wu, D. W. Pang, M. Li Wang et al., "Effect of Mongolia drug TGLG-1 on serum lipids in hyperlipidemic rats," Chinese Journal of Modern Drug Application, vol. 23, no. 4, pp. 272274, 2006.

[71] R. Wen, C. J. Zhou, Y. B. Jia, P. Li, and S. H. Yin, "Effect of quercetin and apigenin on the proliferation and apoptosis of HepG2 cells," Modern Medicine Journal of China, vol. 18, no. 01, pp. 5-8, 2016.

[72] R. Wen, C. J. Zhou, Y. B. Jia, and T. Zhong, "Effects of four flavonoid glycosides in Artemisia lavandulaefolia on the expression of AMPK and LPIN1 in HepG2 cells," Chinese Journal of Pharmaceutical Analysis, vol. 37, no. 01, pp. 74-82, 2017.

[73] Y. Li and C. J. Zhou, "Effects of total flavonoids from Artemisia lavandulaefolia on AMPK related signal transduction pathway in lipid metabolism of HepG2 cells," Chinese Journal of Pharmaceutical Analysis, vol. 39, no. 08, pp. 1396-1403, 2019.

[74] L. G. Fu and T. Q. Chen, Higher Plants of China.13 Volumes, pp. 91-92, Qingdao Publishing House, Qingdao, China, 2002.

[75] Z. Y. Qu, X. Li, and X. Zou, "Purification and antitumor activity of total saponins of Hosta ventricosa," Natural Product Research and Development, vol. 30, no. 08, pp. 1432-1436, 2018.

[76] Y. Xin and Y. H. Bai, "Study on antibacterial activity of ethanol extract of Mongolian medicine flowers of Hosta plantaginea (Lam.) from outside and inside," Chinese Traditional Patent Medicine, vol. 37, no. 3, pp. 653-656, 2015.

[77] W. Y. Li, Preliminary Study on the Chemical Compositions and Bioactivities of Mongolian Medicine Hosta Plantaginea(Lam,) Ascherson, Hua zhong University of Science and Technology, Wuhan, China, 2009.

[78] C. Y. Li, P. F. Xue, M. N. Liu, P. P. Wang, and L. Wang, "Study on the anti-inflammatory effects of Hosta plantaginea in Mice," Lishizhen Medicine and Materia Medica Research, vol. 26, no. 07, pp. 1559-1560, 2015.

[79] J. W. He, L. Yang, J. X. Zhu, X. M. Wang, Z. R. Zou, and W. W. He, "The comparison of anti-inflammatory effects and HLPC detection on different extracts from the flower of Hosta plantaginea in mice," Journal of Jiangxi Normal University (Natural Science Edition), vol. 40, no. 02, pp. 183-185, 2016.

[80] H. X. Xie, P. F. Xue, J. Zhou, L. Fan, and F. H. Yuan, "The research of analgesic action of H.plantaginea in mice," Acta Academiae Medicinae Neimongol, vol. 32, no. 1, pp. 36-38, 2010.

[81] M. M. Wu, X. J. Li, P. F. Xue et al., "Cytotoxic effect of Gitogenin and its three steroidal saponins in Mongolia herbal medicine flos Hostae in vitro," Research and Pactice on Chinese Medicines, vol. 32, no. 02, pp. 16-18, 2018.

[82] J. Q. Liu, C. F. Wang, M. H. Qiu, and W. H. Hu, "Steroidal saponins from flowers of Hosta plantaginea and their antitumor activities," Chinese Traditional and Herbal Drugs, vol. 41, no. 4, pp. 520-526, 2010.

[83] R. Wei, Q. Ma, G. Zhong, J. He, and Z. Sang, "Isolation and characterization of flavonoid derivatives with anti-prostate cancer and hepatoprotective activities from the flowers of Hosta plantaginea (Lam.) Aschers," Journal of Ethnopharmacology, vol. 253, Article ID 112685, 2020.
[84] Y. Q. Ma, Inner Mongolia Flora, pp. 604-606, Inner Mongolia People's Press, Huhhot, China, 1992.

[85] O. urigi, R. Bu, and Q. S. Wu, "Ethnobotanical study of Mongolian medicine Agi," Journal of Chinese Medicinal Materials, vol. 24, no. 6, p. 394, 2001.

[86] Q. Y. Bai, Chinese Medicine Encyclopaedia Mongolian Medicine, pp. 322-324, Inner Mongolia Science \& Technology Press, Chi Feng, China, 1986.

[87] J. J. Chen, S. M. Wang, C. F. Li, Q. W. Shi, M. L. Zhang, and M. Dong, "Studies of sesquiterpenoids from Artemisia frigida on the anti-growth activity of human tumor cell lines," Clinical Journal of Traditional Chinese Medicine, vol. 27, no. 02, pp. 24-26, 2011.

[88] B. Olas and Beata, "The beneficial health aspects of sea buckthorn (Elaeagnus rhamnoides (L.) A.Nelson) oil," Journal of Ethnopharmacology, vol. 213, pp. 183-190, 2018.

[89] N. N. Zhang, R. L. Hou, K. X. Li et al., "Antitumor activity and mechanism of ursolic acid extracted from Hippophae rhamnoides L. On H22 tumor bearing mice," Food Research and Development, vol. 40, no. 10, pp. 6-12, 2019.

[90] C. Grey, C. Widén, P. Adlercreutz, K. Rumpunen, and R. D. Duan, "Antiproliferative effects of sea buckthorn (Hippophae rhamnoides L.) extracts on human colon and liver cancer cell lines," Food Chemistry, vol. 120, no. 4, pp. 1004-1010, 2009.

[91] J. K. Zhang, M. Z. Lin, and X. M. Zhang, "Pharmacodynamics study on extractives from different seabuckthorn organs to solid tumour mice," The Global Sea Buckthorn Research and Development, vol. 10, no. 03, pp. 1-6, 2012.

[92] B. Sun, P. Zhang, W. J. Qu, X. L. Zhang, X. Y. Zhuang, and H. J. Yang, "Study on effect of Flavonoids from oil-removed seeds of Hippophae rhamnoides on inducing apoptosis of human hepatoma cell," Journal of Chinese Medicinal Materials, vol. 12, pp. 875-877, 2003.

[93] S. T. Bao, Y. H. Lu, Z. T. Wang, X. Y. Tao, and D. Z. Wei, "In vitro anti-tumor activity of isorhamnetin isolated from Hippophae rhamnoides L. against BEL-7402 cells," The Pharma Research, vol. 549, no. 3, pp. 186-194, 2006.

[94] J. M. Llovet, A. Villanueva, A. Lachenmayer, and R. S. Finn, "Advances in targeted therapies for hepatocellular carcinoma in the genomic era," Nature Reviews Clinical Oncology, vol. 12, no. 7, pp. 408-424, 2015.

[95] W. Gaowa, S. P. Liu, H. S. Wang, and H. Tao, "A study on Mongolia medicine NaRenManDuLa-11 depressing the proliferation of gastric tumor and its mechanism," China Practical Medicine, vol. 3, no. 13, pp. 18-19, 2008.

[96] X. L. Deng, D. Wang, and S. P. Liu, "The study on the induction of gastric cancer cell apoptosis by the Mongolian medicine NaRenManDuLa-11," The Journal of Practical Medicine, vol. 28, no. 8, pp. 1350-1351, 2012. 